\title{
El contencioso ambiental ${ }^{1}$
}

\author{
Jesús Fordano Fraga
}

Catedrático de Derecho Administrativo

Universidad de Sevilla

\begin{abstract}
SUMARIO: I. INTRODUGGIÓN. II. LEGITIMAGIÓN EN GONTENCIOSOS AMBIENTALES. LA REGULACIÓN DE LA AGGIÓN POPULAR EN LA LEY 27/2006 DE 18 DE JULIO, DE AGGESO A LA INFORMAGIÓN, PARTICIPACIÓN PÚBLICA Y ACGESO A LAJUSTICIA EN MATERIA DE MEDIO AMBIENTE. 1. Ámbito subjetivo: La discutible creación de un monopolio del control jurisdiccional objetivo en los contenciosos ambientales. 2. Ámbito objetivo. III. LA ACGIÓN POPULAR EN LA LEGISLACIÓN AMBIENTAL Y LOS LÍMITES DEL SISTEMA DE LEGITIMACIÓN. 1. La acción popular en la legislación ambiental y los aspectos nucleares del ejercicio de las acciones populares - cosa juzgada, plazo, abuso del derecho, costas-. 2. Los límites del sistema de legitimación, legitimación colectiva, y legitimación activa de los Ayuntamientos y partidos políticos en materia ambiental. A. Los límites del sistema de legitimación. Los procedimientos sancionadores y la posición del denunciante. B. Legitimación colectiva en manos de las asociaciones. C. Legitimación de los Ayuntamientos y partidos políticos. D. La restrictiva legitimación del Ministerio Fiscal. 3. La apertura de la casación por grave daño a los intereses generales. IV. MEDIDAS CAUTELARES. 1. Medio ambiente y tutela cautelar. 2. Obligatoriedad ex artículo $45 \mathrm{CE}$ de adopción de medidas cautelares por la existencia de perjuicios de imposible reparación para el medio ambiente. La prevalencia de los intereses generales (protección medioambiental) frente a los intereses particulares o intereses de tercero. V. A MODO DE CONCLUSIÓN.
\end{abstract}

RESUMEN: El presente estudio analiza el sistema de legitimación y las medidas cautelares en los contenciosos ambientales estudiando en especial la jurisprudencia del TS. El sistema ha sido impactado por la Convención de Arhus y la Ley 27/2006. En un Estado ambiental de Derecho la situación actual debe subvertirse dejando atrás las normas ficción participación-control jurisdiccional posibilidad.

Estudio realizado en el marco del proyecto DER2017-85981-C2-2-R, "Derecho Ambiental, Recursos naturales y Vulnerabilidad", subvencionado por el Ministerio de Economía, Industria y Competitividad. 
Son necesarias normas que regulen el efectivo control con sujetos dotados de status procesal respaldado presupuestariamente.

PALABRAS CLAVE: Justicia ambiental, legitimación activa, acciones populares y medidas cautelares

ABSTRACT: The present study analyzes the system of legitimation and the precautionary measures in environmental disputes analyzing the jurisprudence of the Suprem Court. The system has been impacted by the Arhus Convention and Act 27/2006. In an environmental state of law current situation must subvert leaving behind the norms fiction participation-control jurisdictional possibility. Rules that regulate effective control with subjects endowed with budget-supported procedural status are necessary.

KEY WORDS: Environmental Justice, standing to sue, Cititzen Suits and Precautionary Measures/injuctions

\section{INTRODUCGIÓN}

Aunque de momento no existe en España la jurisdicción ambiental (al menos formalmente, porque hay Salas y Secciones destacadamente "ambientales"), sí comienza a surgir un discurso propio de lo contencioso-ambiental con reglas y principios. Vamos a centrar nuestra atención en dos elementos del contencioso ambiental: legitimación y medidas cautelares². La legitimación es uno de los temas clásicos del Derecho ambiental. En particular, en Estados Unidos el standing ha sido uno de los temas estrella en el nacimiento y evolución del Derecho Ambiental. En todos los ordenamientos el surgimiento del problema ambiental ha impactado con un sistema jurídico procesal diseñado y pensado para defender derechos clásicos y relaciones jurídicas en torno al derecho subjetivo por excelencia: el derecho de propiedad. Las nuevas relaciones jurídicas, el surgimiento de sujetos colectivos - asociacionismo ecológico- y las nuevas generaciones de derechos han provocado una larga lucha fruto de la cual es la regulación que hoy analizamos. En España, la jurisprudencia había determinado desde el art. 7.2 de la LOPJ una amplia legitimación en los contenciosos ambientales pero con saltos adelante y hacia atrás. También muchas leyes estatales y autonómicas han venido reconociendo la acción popular ambiental. En este background se insertan la Ley 29/1998, de 13 de julio, Reguladora de la Jurisdicción Con-

2 Nos basamos en dos previos trabajos que revisamos y ponemos al día en Doctrina, jurisprudencia y datos normativos: nuestro libro La Protección del derecho a un Medio Ambiente Adecuado, Ed. Bosh Barcelona 1995 y Análisis de la Ley 27/2006 en cuanto al acceso a la justicia, en especial el principio de legitimación en los contenciosos ambientales, "Estudios de derecho judicial", ISSN 1137-3520, N". 137, 2007 (Ejemplar dedicado a: Examen del a nueva Ley de acceso a la información, participación pública y acceso a la justicia en materia de medioambiente), pp. 115-140. 
tencioso-administrativa y la Ley 27/2006 de 18 de julio, de acceso a la información, participación pública y acceso a la justicia que regulan de forma cicatera la legitimación en contenciosos ambientales instaurando, en nuestra opinión, un desfasado neocorporativismo.

El derecho que vamos analizar realiza la transposición de la Directiva 2003/4/ CE, del Parlamento Europeo y del Consejo, de 28 de enero de 2003, sobre el acceso del público a la información ambiental, y de la Directiva 2003/35/CE, del Parlamento Europeo y del Consejo, de 26 de mayo de 2003, por la que se establecen medidas para la participación del público en determinados planes y programas relacionados con el medio ambiente y por la que se modifican, en lo que se refiere a la participación pública y el acceso a la justicia, las Directivas 85/337/CEE y 96/61/ CE. Este además es el derecho interno que da cumplimiento al Convenio de la Comisión Económica para Europa de Naciones Unidas sobre acceso a la información, la participación del público en la toma de decisiones y el acceso a la justicia en materia de medio ambiente, hecho en Aarhus el 25 de junio de 1998, más conocido como Convenio de Aarhus. En concreto se trata de la legislación que da contenido a las exigencias del artículo 9 del Convenio de Aarhus ${ }^{3}$. Recordemos que con arreglo al aparto 5, del artículo 2 del Convenio, "público interesado."

3 Este precepto dispone en su apartados 2 y ss: Artículo 9. Acceso a la justicia.

2. Cada Parte velará, en el marco de su legislación nacional, por que los miembros del público interesado:

a) que tengan un interés suficiente o, en su caso,

b) que invoquen la lesión de un derecho, cuando el Código de procedimiento administrativo de una Parte imponga tal condición, podrán interponer recurso ante un órgano judicial u otro órgano independiente e imparcial establecido por la Ley para impugnar la legalidad, en cuanto al fondo y en cuanto al procedimiento, de cualquier decisión, o cualquier acción u omisión que entre en el ámbito de las disposiciones del artículo 6 y, si el derecho interno lo prevé y sin perjuicio de lo dispuesto en el apartado 3 infra, de otras disposiciones pertinentes del presente Convenio.

Lo que constituye interés suficiente y lesión de un derecho se determinará con arreglo a las disposiciones del derecho interno y conforme al objetivo de conceder al público interesado un amplio acceso a la justicia en el marco del presente Convenio. A tal efecto, el interés de toda organización no gubernamental que cumpla las condiciones previstas en el apartado 5 del artículo 2 se considerará suficiente en el sentido de la letra a) supra. Se considerará igualmente que esas organizaciones tienen derechos que podrían ser lesionados en el sentido de la letra b) supra.

Las disposiciones del presente apartado 2 no excluyen la posibilidad de presentar un recurso preliminar ante una autoridad administrativa ni eximen de la obligación de agotar las vías de recurso administrativo antes de entablar un procedimiento judicial cuando el derecho interno imponga tal obligación.

3. Además, sin perjuicio de los procedimientos de recurso a que se refieren los apartados 1 y 2 supra, cada Parte velará por que los miembros del público que reúnan los eventuales criterios previstos por su derecho interno puedan entablar procedimientos administrativos o judiciales para impugnar las acciones $u$ omisiones de particulares o de autoridades públicas que vulneren las disposiciones del derecho medioambiental nacional. 
"A los efectos de la presente definición, se considerará que tienen tal interés las organizaciones no gubernamentales que trabajan en favor de la protección del medio ambiente y que cumplen los requisitos exigidos por el derecho interno".

Como fácilmente puede observarse el artículo 23 de la Ley 27/2006 es ese derecho interno siguiendo esa amplia libertad que el Convenio confiere a los Estados. La cuestión objeto de nuestro interés es regulada en los artículos 22 y 23 de la Ley 27/2006 de 18 de julio. Veamos estos preceptos:

\section{Artículo 22. Acción popular en asuntos medioambientales.}

Los actos y, en su caso, las omisiones imputables a las autoridades públicas que vulneren las normas relacionadas con el medio ambiente enumeradas en el artículo 18.1 podrán ser recurridas por cualesquiera personas jurídicas sin ánimo de lucro que reúnan los requisitos establecidos en el artículo 23 a través de los procedimientos de recurso regulados en el Título VII de la Ley 30/1992, de 26 de noviembre, de Régimen Jurídico de las Administraciones Públicas y del Procedimiento Administrativo Común, así como a través del recurso contencioso-administrativo previsto en la Ley 29/1998, de 13 de julio, Reguladora de la Jurisdicción Contencioso-Administrativa.

Se exceptúan los actos y omisiones imputables a las autoridades públicas enumeradas en el artí́culo 2.4.2.

\section{Artículo 23. Legitimación.}

1. Están legitimadas para ejercer la acción popular regulada en el artículo 22 cualesquiera personas jurídicas sin ánimo de lucro que acrediten el cumplimiento de los siguientes requisitos:

a) Que tengan entre los fines acreditados en sus estatutos la protección del medio ambiente en general o la de alguno de sus elementos en particular.

4. Además, sin perjuicio de lo dispuesto en el apartado 1, los procedimientos a que se refieren los apartados 1, 2 y 3 supra deberán ofrecer recursos suficientes y efectivos, en particular una orden de reparación, si procede, y deberán ser objetivos, equitativos y rápidos sin que su costo sea prohibitivo. Las decisiones adoptadas en virtud del presente artículo se pronunciarán o consignarán por escrito. Las decisiones de los tribunales y, en lo posible, las de otros órganos deberán ser accesibles al público".

5. Para que las disposiciones del presente artículo sean aún más eficaces, cada Parte velará por que se informe el público de la posibilidad que se le concede de iniciar procedimientos de recurso administrativo o judicial, y contemplará el establecimiento de mecanismos de asistencia apropiados encaminados a eliminar o reducir los obstáculos financieros o de otro tipo que obstaculicen el acceso a la justicia”. 
b) Que se hubieran constituido legalmente al menos dos años antes del ejercicio de la acción y que vengan ejerciendo de modo activo las actividades necesarias para alcanzar los fines previstos en sus estatutos.

c) Que según sus estatutos desarrollen su actividad en un ámbito territorial que resulte afectado por la actuación, o en su caso, omisión administrativa.

2. Las personas jurídicas sin ánimo de lucro a las que se refiere el apartado anterior tendrán derecho a la asistencia jurídica gratuita en los términos previstos en la Ley 1/1996, de 10 de enero de Asistencia Jurídica Gratuita.

Sin duda, una de las novedades es el reconocimiento a estos "actores populares" del derecho a la asistencia jurídica gratuita en los términos previstos en la Ley 1/1996, de 10 de enero de Asistencia Jurídica Gratuita. Los problemas e insuficiencias del tal reconocimiento serán analizados más adelante.

Debemos reseñar que estos criterios (fines estatutarios y desarrollo de la actividad en el ámbito territorial afectado) se han extendido a la interpretación de la concurrencia de los intereses legítimos colectivos. En este sentido, la STS de 9 de octubre de 2012, (Sala de lo Contencioso-Administrativo, Sección $3^{\text {a }}$ ), Recurso de Casación 110/2009, Ponente CAMPOS SÁNCHEZ-BORDONA, $\mathrm{RJ} \backslash 2012 \backslash 9648$, f. de Dcho $3^{\circ}$, entiende que una asociación de vecinos está legitimada para recurrir la improcedencia de excluir de un trámite de evaluación ambiental-en principio obligado- un determinado proyecto, precisamente por entender que la construcción del centro penitenciario infringía, entre otras, las normas urbanísticas comarcales y municipales en la medida en que se trata de una asociación vecinal cuyo ámbito geográfico se enmarca dentro del mismo término territorial en que se proyecta el centro penitenciario y entre cuyos fines estatutarios se encuentra el de promover la mejora del entorno urbanístico.

\section{1. Ámbito subjetivo: La discutible creación de un monopolio del control jurisdiccional objetivo en los contenciosos ambientales}

Es obvio que el régimen establecido no determina una verdadera acción popular/pública que, por definición, supondría la desaparición de los requisitos de legitimación. Estamos ante una legitimación restringida a sujetos colectivos y no a todos los sujetos colectivos. Desde este punto de vista subjetivo, la legitimación se restringe a

- cualesquiera personas jurídicas sin ánimo de lucro

- que tengan entre los fines acreditados en sus estatutos la protección del medio ambiente en general o la de alguno de sus elementos en particular. 
- que se hayan constituido legalmente al menos dos años antes del ejercicio de la acción y que vengan ejerciendo de modo activo las actividades necesarias para alcanzar los fines previstos en sus estatutos.

- que según sus estatutos desarrollen su actividad en un ámbito territorial que resulte afectado por la actuación, o en su caso, omisión administrativa ${ }^{4}$.

Igualmente, restrictivo es el criterio de la antigüedad de dos años que pretende eliminar la posibilidad de constitución de asociaciones ad hoc para un caso judicial concreto. La inspiración está en el sistema francés de reconocimiento de asociaciones El reconocimiento o habilitación (agrément) tuvo su origen en 1976 para seleccionar las asociaciones beneficiarias de derechos especiales de participación en la política ambiental. Aunque pocas asociaciones han solicitado el reconocimiento y los poderes públicos no han reservado la exclusividad del derecho a la participación a las asociaciones reconocidas. Los criterios de reconocimiento se refieren a la antigüedad en su funcionamiento y a su representatividad. La duración del funcionamiento de la asociación susceptible de ser reconocida ha de ser de al menos tres años, a contar desde su declaración en la Prefectura o de su inscripción en el Registro de asociaciones del Tribunal civil, en los Departamentos del Bas Rhin, Haut Rhin y Moselle. Estos criterios pretenden garantizar según PRIEUR, que las asociaciones no sean artificiales o meramente políticas. Según el Decreto de 7 de julio de 1977, art. R 252 - 2 del Code Rural, la representatividad será apreciada discrecionalmente por la Administración teniendo en cuenta tres factores: -El funcionamiento de la asociación conforme a sus estatutos.-Que se trate de actividades desinteresa-

$4 \quad$ Es fácil detectar los precedentes inspiradores de esta regulación. En este sentido, la entonces Ley 9/2006, de 28 abril, sobre evaluación de los efectos de determinados planes y programas en el medio ambiente estableció al regular el público interesado en las consultas dentro del marco de participación

Artículo 10. Consultas.

2. A los efectos de esta Ley, se entenderá por público interesado:

a) Toda persona física o jurídica en la que concurra cualquiera de las circunstancias previstas en el artículo 31 de la Ley 30/1992, de 26 de noviembre, de Régimen Jurídico de las Administraciones Públicas y del Procedimiento Administrativo Común.

b) Cualquier persona jurídica sin ánimo de lucro que cumpla los siguientes requisitos:

$1^{\circ}$ Que tenga como fines acreditados en sus estatutos, entre otros, la protección del medio ambiente en general o la de alguno de sus elementos en particular, y que tales fines puedan resultar afectados por el plan o programa de que se trate.

$2^{\circ}$ Que lleve al menos dos años legalmente constituida y venga ejerciendo de modo activo las actividades necesarias para alcanzar los fines previstos en sus estatutos. Hoy están el art. 5, letra g) apartado $2^{\circ}$ de la Ley 21/2013, de 9 de diciembre, de evaluación ambiental. A favor de la exigencia de estos requisitos excluyendo los ciudadanos, ORTEGA BERNARDO, J. ¿Quién ha apostado por la efectiva implantación del derecho de acceso a la justicia a favor de las organizaciones no gubernamentales en defensa del medio ambiente?", Actualidad Furídica Ambiental, No. 6 (Octubre), 2011, pp. 8 y 10 
das en favor de la naturaleza, el medio ambiente o el marco de vida. Que exista una organización que ofrezca garantías suficientes ${ }^{5}$. La técnica de exigencia de una determinada antigüedad nos parece ilusa, pues será fácilmente burlada mediante el interesamiento cooperativo de una asociación existente que cumpla el requisito temporal. Las exigencias estatutarias son conocidas en el Derecho comparado (por ejemplo, Francia) y han sido una constante como parámetro de la legitimación colectiva en España.

Es ciertamente llamativo el establecimiento del criterio de la conexión territorial. La procedencia en este caso es el derecho anglosajón. En Sierra Club v. Morton $^{6}$ (el asunto fue planteado ante la Suprem Court el 17 de noviembre de 1971 y fue decidido el 19 de abril de 1972) se trataba de enjuiciar una decisión del Forest Service de aprobar un proyecto de la Walt Disney Enterprises Inc. para construir una autopista y un complejo (fundamentalmente una estación de esquí y un área de recreo veraniega) de moteles, restaurantes y otras estructuras acomodadas para una capacidad de catorce mil visitantes diarios, en el Mineral King Valley ${ }^{7}$.

Siguiendo esta metodología la Suprem Court ha aceptado la legitimación de determinadas asociaciones ecologistas (así, por ejemplo en United States $v$. Students Challenging Regulatory Agency Procedures, sentencia dictada el 18 de junio de 1973, se enjuiciaba la pretensión de un grupo ambiental de prohibir las órdenes de la Interstate Comerce Comission, de permitir a los ferrocarriles percibir adicionalmente una sobretasa proporcional del 2’5\% en los fletes de carga estando pendiente la adopción de incrementos selectivos). Así pues, en esta sentencia la Corte Suprema consideró que SCRAP poseía standing. En su opinión a diferencia de Sierra Club, "los apelados reclamaron que la específica y presuntamente acción ilegal de la Comisión les perjudicaría directamente en su disfrute de los recursos naturales del área metropolitana de Washington ${ }^{8} "$.

La Ley 27/2006 importando criterios ajenos a nuestra tradición jurídica contrasta con nuestra jurisprudencia que se ha caracterizado por el reconocimiento de una amplia legitimación en contenciosos ambientales ${ }^{9}$. La Ley 27/2006 configura

\footnotetext{
PRIEUR M., Droit de l'environnement, Dalloz Paris 1984, p. 9. 405 U.S. 727 (1972), 92 S.Ct. 1361.

7 Véase nuestra obra La Protección de Derecho a un Medio Ambiente adecuado, cita, pp. $360-$ 362.

8 Vid. La Protección de Derecho a un Medio Ambiente adecuado, cita, pp. 363-364. .

9 Así podemos encontrar poderosos precedentes: Como sentencias favorables al reconocimiento de una legitimación amplia en contenciosos ambientales deben citarse las sentencias de 24 de septiembre de 1975 (Ar. 3754, Ponente De MENDIZÁBAL y ALLENDE), 8 de mayo de 1979, Ar. 2389 (Sala 4ª , Ponente MEDINA BALMASEDA) y 25 de abril de 1989, Ar. 3233 (Sala 3 ${ }^{\text {a }}$, Ponente GONZÁLEZ NAVARRO). La sentencia del Tribunal Supremo de 25 de abril de 1989 (LA LEY 727-JF/0000) reconoce legitimación a una persona (suponiendo su condición de vecino) para impugnar un acuerdo municipal sobre vertido de aguas
} 
la resurrección de una legitimación corporativa sobre sujetos colectivos ecologistas creando un discutible monopolio del control jurisdiccional objetivo en los contenciosos ambientales. Sin embargo, sentencias como la STS de 1 de diciembre de 2009, Tribunal Supremo, Sala Tercera, de lo Contencioso-administrativo, Sección Pleno, Rec. 55/2007, Ponente ESPÍN TEMPLADO, LA LEY 233150/2009, f. de Dcho $2^{\circ}$, muestran el impacto positivo pro legitimación de la Ley 27/2006-la ley 27/2006 disipa dudas legitimación en asociaciones ecologistas carácter nacional-. Frente a la negación en la instancia de legitimación activa a Ecologistas en Acción y Greenpeace España, el TS invoca los criterios de la Ley 27/2006 para afirmar dicha legitimación con rotundidad.- , cuyos artículos 22 y 23 la "otorgan indiscutiblemente". Esto muestra que el retroceso que ha impuesto la Ley 27/2006 no es lineal -frente a lo conquistado ex 7.2LOPJ-, pues al menos actúa como elemento disipador de las dudas que puedan existir en materia de legitimación en contenciosos ambientales.

\section{2. Ámbito objetivo}

En cuanto al ámbito objetivo es fácil igualmente detectar las exigencias. Bajo el ámbito objetivo o ratione materiae de esta presunta "acción popular" se encuentran

- Los actos y, en su caso, las omisiones

- imputables a las autoridades públicas

- que vulneren las normas relacionadas con el medio ambiente

- enumeradas en el artículo 18.1

son controlables los actos y las omisiones. Falta una expresa mención a las vías de hecho, que es obvio que deben entenderse incluidas por estar bajo el control de la jurisdicción contencioso-administrativa. Las autoridades públicas son definidas en el apartado 4, del art. 2. este precepto las define en los siguientes términos:

fecales. La sentencia invoca, en apoyo de sus conclusiones, el reconocimiento por la Constitución, en su artículo 45, del derecho de todos a un medio ambiente adecuado. A su vez, la sentencia del Tribunal Supremo de 12 de febrero de 1990 (LA LEY 26131-JF/0000), reconoce legitimación a un vecino de la localidad para impugnar la licencia de instalación de una granja que produce fuertes olores que suponen molestias para los vecinos, incluso relativamente alejados de la instalación. Mas recientemente lo ha hecho la STS de 22 de abril de 2002, Sala Tercera, de lo Contencioso-administrativo, Sección 4 ${ }^{\text {a }}$, Rec. 3799/1997, Ponente XIOL RÍOS, LA LEY 6202/2002, f. de Dcho $11^{\circ}$, "el ciudadano que ejercita la defensa de un interés difuso puede estar defendiendo su propio círculo vital afectado, cuyo ámbito permite definir el concepto constitucional de interés legítimo. Por ello este Tribunal está abriendo caminos al reconocimiento de este tipo de legitimación cuando se aprecia un punto de conexión con el círculo vital de intereses de la corporación, asociación o particular recurrente. Frecuentemente, este punto de conexión son las relaciones de vecindad". 
4. Autoridades públicas:

1. Tendrán la condición de autoridad pública a los efectos de esta Ley:

a) El Gobierno de la Nación y los órganos de gobierno de las Comunidades Autónomas.

b) La Administración General del Estado, las Administraciones de las Comunidades Autónomas, las Entidades que integran la Administración local y las Entidades de Derecho Público que sean dependientes o estén vinculadas al Estado, a las Comunidades Autónomas o a las Entidades locales.

c) Los órganos públicos consultivos.

d) Las Corporaciones de derecho público y demás personas físicas o jurídicas cuando ejerzan, con arreglo a la legislación vigente, funciones públicas, incluidos Notarios y Registradores de la Propiedad, Mercantiles y de Bienes Muebles.

2. Tendrán la condición de autoridad pública, a los solos efectos de lo previsto en los Títulos I y II de esta Ley, las personas físicas o jurídicas cuando asuman responsabilidades públicas ejerzan funciones públicas o presten servicios públicos relacionados con el medio ambiente bajo la autoridad de cualquiera de las entidades, órganos o instituciones previstos en el apartado anterior.

3. Quedan excluidos del concepto de autoridad pública las entidades, órganos o instituciones cuando actúen en el ejercicio de funciones legislativas o judiciales. En todo caso, cuando actúen en el ejercicio de funciones legislativas o judiciales, quedan excluidos del ámbito de aplicación de esta Ley las Cortes Generales, las Asambleas Legislativas de las Comunidades Autónomas, el Tribunal Constitucional, los juzgados y tribunales que integran el Poder Judicial, el Tribunal de Cuentas u órganos de fiscalización externa de las Comunidades Autónomas.

Obsérvese que este precepto está destinado a superar la regulación de la Ley 38/1995, de 12 de diciembre, sobre el derecho de acceso a la información en materia de medio ambiente. Esta regulación hoy derogada establecía que la información en poder de la administración instrumental o un concesionario debía ser recabada mediante su solicitud a la administración matriz. La Ley limita en consonancia este concepto a los efectos de los Títulos I y II. Es obvio que de aquí no puede colegirse que estas personas jurídicas-privadas que ejerzan funciones públicas o presten servicios están fuera de la acción popular. Recordemos que en la jurisprudencia constitucional frente a la sociedad estatal RTVE (ente que el TC califica de interpuesto, "persona interpuesta, pero en modo alguno independiente") cabe amparo frente a sus decisiones 
(STG 35/1983, de 11 de mayo ${ }^{10}$, f.j. núm. 3, Ponente RUBIO LLORENTE) ${ }^{11}$. Pero la doctrina jurisprudencial estudiada y la consideración como poderes públicos de estos entes interpuestos ha de aplicarse también a las sociedades mercantiles de titularidad pública. El planteamiento puede ser llevado hasta sus últimas consecuencias predicando la revisión jurisdiccional respecto de sociedades controladas o vinculadas, con independencia de la titularidad (en el plano subjetivo) y, sobre todo, prescindiendo de la existencia formal de un acuerdo societario (en el plano objetivo). Si el control procede frente a las vías de hecho y omisiones de la Administración, habrá de admitirse la consiguiente lógica susceptibilidad de amparo frente las vías de hecho y omisiones de los entes interpuestos. Quizá esto sea todavía insuficiente y resulte preciso profundizar en una teoría realista del control jurisdiccional. El levantamiento del velo es una técnica formal y puede ser necesario una perspectiva material en la noción de poder público. Habrá de ponerse entonces el acento en las funciones. En Gran Bretaña desde el Data fin case ${ }^{12}$, al objeto de determinar el ámbito del judicial review, la doctrina sentada es la siguiente: las decisiones tomadas por empresas privadas a las que han sido delegadas potestades públicas son susceptibles de control jurisdiccional (judicial review) si están llevando a cabo tareas o deberes de naturaleza pública, de forma, que si no los desempeñasen, el gobierno estaría obligado a proporcionar para esas funciones alguna estructura legislativa. Es el test funcional (la pregunta clave es si el ente de acuerdo con su status legal lleva acabo un deber público) ${ }^{13}$. Esto en el campo del medio ambiente es especialmente necesario dado el repliegue de lo público mediante la privatización de servicios públicos y la delegación de funciones públicas a sujetos privados.

Por último, procede analizar el ámbito objetivo material que se realiza por remisión. Son las materias enumeradas en el artículo 18.1:

\section{Artículo 18. Normas relacionadas con el medio ambiente.}

1. Las Administraciones públicas asegurarán que se observen las garantías en materia de participación establecidas en el artículo 16 de esta Ley en relación con la elaboración,

$10 \quad$ BJC 26/1983, pp. 651-657.

11 Sin embargo, esta línea jurisprudencial ha establecido límites. El ATC 154/1987, de 11 de febrero, considera que no existe lesión del art. $23 \mathrm{CE}$ por el despido de un trabajador en una empresa en la que existe participación pública en el capital. En este caso el cese del actor había obedecido a una causa prevista en norma legal, habiendo sido declarada conforme a ella por los órganos judiciales.

12 Rv Panel on Take-overs and Mergers ex parte Datafin (1987) 2 WLR 669.

13 vid. Cosmo GRAHAM, Towards a european administrative law? The english case, "R.T.D.P." 1/1993, p. 5. La doctrina ha sido extendida con posterioridad a la Advertising Standards Authority pero no al fockey Club ni a la Football Association a pesar de que pueda afirmarse que al menos en parte estos últimos entes desempeñen, al menos en cierta medida, funciones públicas. 
modificación y revisión de las disposiciones de carácter general que versen sobre las materias siguientes:
a) Protección de las aguas.
b) Protección contra el ruido.
c) Protección de los suelos.
d) Contaminación atmosférica.
e) Ordenación del territorio rural y urbano y utilización de los suelos.
f) Conservación de la naturaleza, diversidad biológica.
g) Montes y aprovechamientos forestales.
h) Gestión de los residuos.
i) Productos químicos, incluidos los biocidas y los plaguicidas.
j) Biotecnología.
k) Otras emisiones, vertidos y liberación de sustancias en el medio ambiente.
l) Evaluación de impacto medioambiental.
m) Acceso a la información, participación pública en la toma de decisiones y acceso a la justicia en materia de medio ambiente.

n) Aquellas otras materias que establezca la normativa autonómica.

Es criticable esta forma de legislación por remisión que llevar a reconocer la acción popular en materia de acceso a la justicia. O que reduce la acción popular en urbanismo -ésta sí verdadera acción popular-. Pero cualquier reducción quedaría derogada por la lex posterior y especialis de la Ley estatal del Suelo-. Por otro lado, dado que no es una verdadera acción popular sus límites no son aplicables en libertad de información ni obviamente al urbanismo en el que si existe una verdadera acción popular. Por lo demás, como toda lista es incompleta: no están la evaluación ambiental estratégica ${ }^{14}$-explícitamente-, la autorización ambiental integrada, ni la EMAS ni la ecoetiqueta de modo expreso frente a la EIA que si aparece de modo expreso. No está tampoco la contaminación lumínica de modo expreso. Estos problemas los genera una deficiente técnica legislativa de regulación por remisión sin pensar en las consecuencias de la remisión. Es claro que ninguna restricción debe extraerse de esas limitaciones irreflexivas de la Ley. La jurisprudencia ha sido restrictiva interpretando el ámbito objetivo. Así,

14 Exclusión lógica pues para ella existe acción popular sin límites corporativos. Cfr. ar. 5 letra "f)" del Real Decreto Legislativo 7/2015, de 30 de octubre, por el que se aprueba el texto refundido de la Ley de Suelo y Rehabilitación Urbana. Lo lógico sería precisar con un "sin perjuicio de la acción pública reconocida en la legislación urbanística" pues la acción popular se extiende a EIA de proyectos urbanísticos. Por acción pública debe entenderse, siguiendo la definición que aporta el Diccionario del español jurídico de la RAE y el CGPJ, "la legitimación que ostenta cualquier ciudadano, en ejercicio de la acción popular, para interponer un recurso contencioso-administrativo en materia urbanística y en determinados supuestos relativos al patrimonio histórico-artístico y al medioambiente" (https://www.iberley.es/temas/accion-publica-urbanistica-62165). Desde el punto de vista terminológico acción pública y popular son sinónimos en la legislación administrativa. 
por ejemplo, la STS 33/2018 de 16 de enero de 2018, Sala Tercera, de lo Contencioso-administrativo, Sección $3^{\text {a }}$, Rec. 4464/2015, Ponente Calvo Rojas, LA LEY 370/2018, acción "colectiva" de la Ley 26/2007 se constriñe a las materias allí enunciadas excluyendo el análisis de lo no ambiental (vulneraciones de la ley del Sector eléctrico) en el recurso planteado por la Asociación de vecinos, consumidores y usuarios del Remediu contra la Orden IET/2209/2015, de 21 de octubre que publica el Acuerdo del Consejo de Ministros de 16 de octubre de 2015 por el que se aprueba el Plan de Desarrollo de la Red de Transporte de Energía Eléctrica 2015-2020. El TS declara que "tal reconocimiento de la legitimación para recurrir (legitimación ad processum) no significa que la recurrente puede suscitar cuestiones ni aducir motivos de nulidad ajenos al ámbito medioambiental al que se circunscribe aquella legitimación. Por tanto, y aun no concurriendo causa para la inadmisión del recurso, habrán de ser desestimados aquellos motivos de anulación basados en la vulneración de la Ley 24/2013, del Sector Eléctrico, de la Orden IET/1045/2014, por venir referidos a cuestiones que no están comprendidas en el ámbito de la legitimación resultante de lo dispuesto en los artículo artículos 18, 22 y 23 de la Ley 27/2006, de 18 de julio, y dado que la recurrente tampoco ha justificado debidamente la imbricación de esas vulneraciones que alega de la normativa del sector eléctrico con la materia medioambiental que constituye su título de legitimación” (f. de Dcho $2^{\circ}$ ). Obsérvese que la negativa pro futuro da pie a que si se razona imbricación ambiental se abra la posibilidad de estimar presente la legitimación. Lo que no entendemos es la falta de una interpretación pro actione sobre la base de la posible existencia de intereses legítimos colectivos en este caso en una asociación de vecinos, consumidores y usuarios.

\section{LA AGGIÓN POPULAR EN LA LEGISLAGIÓN AMBIENTAL Y LOS LÍMITES DEL SISTEMA DE LEGITIMAGIÓN}

\section{La acción popular en la legislación ambiental y los aspectos nucleares del ejercicio de las acciones populares -cosa juzgada, plazo, abuso del derecho, costas-}

Dado que la regulación que acabamos de examinar no constituye una verdadera acción popular no está de más que examinemos las verdaderas acciones populares que hoy reconoce la legislación ambiental. Destacan en este sentido en la legislación estatal las reconocidas en el artículo 109 de la Ley 22/1988, de Costas - que reconoce el derecho al abono de los gastos en que se hubiera incurrido-; el artículo 8 de la Ley 16/1985, de 25 de junio de Patrimonio Histórico. Pero sobre todo, debemos destacar el art. 5 letra "f)" del Real Decreto Legislativo 7/2015, de 30 de octubre, por el que se aprueba el texto refundido de la Ley de Suelo y Rehabilitación Urbana que reconoce a todos los ciudadanos el derecho a ${ }^{6}$ 
Ejercer la acción pública para hacer respetar las determinaciones de la ordenación territorial y urbanística, así como las decisiones resultantes de los procedimientos de evaluación ambiental de los instrumentos que las contienen y de los proyectos para su ejecución, en los términos dispuestos por su legislación reguladora".

Obsérvese que en un corto espacio temporal el legislador estatal pasa en EIA y EAE de un sistema de legitimación restringida al de acción pública. En 1995 ya decíamos que el reconocimiento de la acción popular era arbitrario y contradictorio $^{15}$. En 2018 seguimos en las mismas ¿Cómo se puede variar de criterio en un año en algo tan importante?

En la legislación autonómica numerosas normas han reconocido la acción popular $^{16}$. De modo general - estableciéndola con carácter horizontal para todo lo ambiental- así ha procedido la Ley Vasca 3/1998, de 27 de febrero, en su artículo, 3.4 y el artículo 8 de la Ley Foral 4/2005, de 22 de marzo, de Intervención para la protección ambiental. Numerosas normas autonómicas "sectorialmente" han introducido acciones populares en materia de ruido, atmósfera-Galicia y Cataluña-, vías pecuarias, espacios naturales protegidos, flora y fauna.

Todo ello nos lleva a una importante cuestión. ¿Pueden las CCAA introducir acciones populares ${ }^{17}$ ? El TC lo ha negado en otros sectores como el consumo al establecer que la introducción de una acción popular constituye una competencia exclusiva del Estado por tratarse de legislación procesal (STG 71/82 y 173/1998) ${ }^{18}$. En medio ambiente el art. 149.123 CE permitiría resultados distintos, si conceptuáramos dicha introducción como una medida adicional de protección. La cuestión es discutible. Sobre todo porque el dogma de la legitimación afirmado el principio de sometimiento pleno a la Ley y al Derecho de la Administración es especialmente discutible. Nosotros pensamos que el art. $45 \mathrm{CE}$ debe implicar la desaparición de los requisitos de legitimación. Pero esto como veremos lo rechaza expresamente el TS en $2007^{19}$.

15 La Protección del Derecho a un Medio ambiente adecuado, Bosch Madrid 1995, pp. 316.

16 Los últimos recuentos han sido realizados por REGO BLANCO, M. D. La acción popular en derecho administrativo y en especial, en el derecho urbanistico IAAP, Sevilla 2005, cuyo anexo I, pp. 485-518 transcribe los preceptos instauradores y RAZQUIN LIZARRAGA \& RUIZ DE APODACA, Información, Participación y Fusticia en materia de Medio ambiente, Thomson-Aranzadi, Cizur Menor Navarra 2007, pp. 394-397.

17 Al respecto véase nuestra obra citada (1995: 328-334).

18 La cuestión ha podido ser resuelta por la STG 151/2012 de 5 de julio de 2012, Pleno, Rec. 6588/2011, Ponente GAY MONTALVO, LA LEY 105484/2012 pero el TG declaró la extinción de la cuestión de inconstitucionalidad planteada por el TSJ País Vasco en relación con el art. 3.4 de la Ley 3/1998 de 27 de febrero de protección del medio ambiente del País Vasco, por desaparición de su objeto, como consecuencia de la finalización por desistimiento de la parte recurrente.

19 1995: 296-301,453-455, 483-484. 
Existiendo acción pública no procede discriminar aspectos sobre los recurrentes ostentan legitimación reforzada- El TS entiende que la legitimación, basada en el ejercicio de la acción pública, es una e inescindible y afecta por tanto al objeto impugnatorio en su integridad, de suerte que no es dable requerir cuando se impugna un plan urbanístico una legitimación reforzada o, dicho de otro modo, la prueba de un interés legítimo más intenso a la hora de diferenciar qué previsiones del Plan estarían amparadas en la legitimación y cuales otras no lo estarían, con el indeseable efecto procesal de que tendría cabida una especie de inadmisibilidad parcial -STS de 15 de julio de 2015, (Sala de lo Contencioso-Administrativo, Sección $5^{\mathrm{a}}$ ), Recurso de Casación 3492/2013, Ponente NAVARRO SANGHÍS, RJ 2015\3486, f. de Dcho $4^{\circ}$-. En definitiva, solo la existencia de una verdadera acción popular elimina los obstáculos al proceso y la presencia de una causa de inadmisibilidad derivada de la falta de legitimación. Así, la Sentencia de 19 de octubre de 2011, Sala Tercera, de lo Contencioso-administrativo, Sección 5a , Rec. 4630/2007, Ponente PECES MORATE, LA LEY 229002/2011, f. de Dcho 6 ${ }^{\circ}$, respalda la legitimación activa "Institució altempordanesa per a l'estudi i defensa de la natura" (IADEN) para recurrir la resolución, de 8 de noviembre de 2002, de la Consejería de Medio Ambiente de la Generalidad de Cataluña, por la que se otorgó autorización ambiental a la entidad Ramsalt S.A. para la explotación de una granja porcina en el Mas dels Fils del término municipal de Rabós de L'Empordá desde la acción reconocida en las leyes del suelo Estatal y autonómica ${ }^{20}$.

Ya en el plano de los problemas que plantean el ejercicio de las acciones populares conviene repasar de la mano de REGO BLANCO ${ }^{21}$ los límites al ejercicio de las mismas: en cosa juzgada se admite la cosa juzgada formal pero no la cosa juzgada material que solo se producirá entre las partes. En cuanto al plazo si los actos son notificados rigen los plazos generales. Si debió ser notificado el acto pero no lo fue, rige el régimen de las notificaciones defectuosas (STS de 5 de julio de 1999). También rigen los plazos generales si se ha tenido conocimiento del expediente (SSTS de 17 de febrero de 2001 y 30 de noviembre de 2002). Mas importante es el régimen de la presencia de un posible abuso de derecho en su ejercicio. La jurisprudencia se ha movido entre estimar una casa de inadmisión si ha existido abuso del derecho; o desestimar la acción. Son las STS de 22 de enero de 1980 -el fin perseguido por el ejercicio de la acción es causar mal- y 2 de noviembre de 1989 -la existencia de un sentimiento

20 Así, la STS de 20 de noviembre de 2015, Sala Tercera, de lo Contencioso-administrativo, Sección 5a , Rec. 1203/2014, Ponente SUAY RINCÓN, LA LEY 190983/2015, f de Dcho 2, admite la legitimación de la Asociación "Salvemos Pontevedra "para demandar, el inicio del correspondiente procedimiento administrativo dirigido a obtener la declaración de caducidad de la concesión demanial con destino a la instalación de una fábrica de cloro y anexos. La citada asociación sustenta su recurso al amparo del ejercicio de la acción pública reconocida por la Ley de Costas (artículo 109).

21 REGO BLANCO, M. D. (2005, pp. 337-392). 
personal-. Mas moderna nos parece la STSJ de Cantabria de 24 de julio de 2000 en la que se afirmó que el abuso de derecho no impide que prospere la acción popular si existe un beneficio público o si la actuación es ilegal. En cuanto a las costas rigen las reglas generales (STS de 24 de abril de 1997). No obstante, debiera extenderse la doctrina existente en el ámbito penal que excluye de las costas al actor popular en defensa de intereses difusos (Sentencias del Tribunal Supremo 703/2001, de 28 de abril y 515/1999, de 29 de marzo; STS de 2 de julio de 2009, Sala Segunda, de lo Penal, recurso 11521/2008, etc).

\section{Los límites del sistema de legitimación, legitimación colectiva, y legitimación activa de los Ayuntamientos en materia ambiental}

A. Los límites del sistema de legitimación. Los procedimientos sancionadores y la posición del denunciante

La jurisprudencia ha interpretado de forma amplia la legitimación en los contenciosos ambientales de la mano de los artículos 7.3 LOPJ y 19 LRJCA. Realmente los problemas se han planteado en la legitimación del denunciante. Esto es, se rechaza la legitimación de una asociación ecologista, salvo que esté reconocida la acción popular para recurrir actos que determinan sanciones inferiores o que comportan la decisión de no sancionar ${ }^{22}$. Ejemplos paradigmáticos son la STSJ del País vasco de 23 de marzo de 2000, RJCA 1912. O la STS de 16 de junio de 2007, Sala de lo contencioso-administrativo, Sección Quinta, Ponente YAGÜE GIL, dictada en el recurso de casación núm. 8001/2003, en su f.j. núm. 4, que merece transcribirse íntegramente:

\section{Cuarto:}

"La Sala de Burgos razona con buen sentido diciendo que el denunciante carece de interés en solicitar en vía judicial que a la entidad ya sancionada por vertido no autorizado se le imponga judicialmente mayor sanción. Y así es en efecto. El interés legítimo en que la legitimación activa consiste (artículo 19.-1 a) de L.J. 29/98 se define como cualquier ventaja que se derive para una persona del pronunciamiento judicial que se solicita. Y en el presente caso ni el demandante ha puesto de manifiesto ni este Tribunal descubre qué ventaja va a obtener aquél del hecho se que imponga una mayor sanción a la entidad ya sancionada, como no sea la del puro interés a que la actuación sea legal. Sin embargo, este puro interés a la legalidad no es una ventaja que afecte al reducto de sus propios intereses, y una buena prueba de ello es que el ordenamiento jurídico no concede una acción pública en materia de protección del

22 Para un análisis exhaustivo de la cuestión véase PEÑALVER i CABRÉ, Les pretensions davant la inactivitat administrativa en materia sancionadora ambiental, Tirant lo Blanch, Valencia 2004, pp. 459-644. 
medio ambiente, ni siquiera en la reciente Ley 27/2006, de 18 de julio, que regula los derechos de acceso a la información, participación y de acceso a la justicia en materia de medio ambiente, la cual en su artículo 22, solo otorga acción popular a la personas jurídicas sin ánimo de lucro y sólo cuando cumplen los requisitos de su artículo 23 .

En consecuencia, carecen de la fuerza convicción los argumentos que contra de la falta de legitimación activa explaya la parte recurrente en su escrito de casación, ya que ni el derecho genérico al medio ambiente adecuado que proclama el artículo 45-1 de la Constitución Española, ni la necesaria interpretación de las normas procesales conforme al principio "pro actione", ni la profesión médica del demandante, ni, en fin, el valor prevalente de defensa del medio ambiente que la jurisprudencia proclama en la adopción de medidas cautelares, pueden otorgar al demandante un interés en una mayor sanción.

Reiteramos aquí a estos efectos las sentencias del Tribunal Supremo citadas por la sala de instancia, de fechas 17 de marzo de 2003, 25 de febrero de 2002 y 23 de abril de 2003, acerca de la falta de legitimación del mero denunciante en expedientes sancionadores, lo que sin duda tiene un hondo designio social a fin de evitar que la potestad sancionadora de la Administración se pueda convertir en una mera disputa entre personas privadas".

Como es sabido la excepción a la doctrina que niega la legitimación al denunciante es cuando se trata de un denunciante perjudicado. Son supuestos en los que el denunciante ha sufrido una mala praxis profesional y recurre la inactividad o clemencia del correspondiente colegio profesional (médico, notarial) -STS de 12 de febrero de 1992, RJ 2817 y STS de 5 de diciembre de 1999, RJ 2000-. También ha seguido esta doctrina el Tribunal Constitucional en un supuesto de un trabajador perjudicado por un accidente de trabajo. Es la STG 143/2000, de 29 de mayo.

La Ley 39/2015 ha procedido a la regulación general de la colaboración del presunto infractor-denunciante. El artículo 62.4 LPAC le otorga beneficios por su «delación». De esta forma, cuando el denunciante haya participado en la comisión de una infracción de esta naturaleza y existan otros infractores, el órgano competente para resolver el procedimiento deberá eximir al denunciante del pago de la multa que le correspondería u otro tipo de sanción de carácter no pecuniario, cuando sea el primero en aportar elementos de prueba que permitan iniciar el procedimiento o comprobar la infracción, siempre y cuando en el momento de aportarse aquellos no se disponga de elementos suficientes para ordenar la misma y se repare el perjuicio causado. Asimismo, el órgano competente para resolver deberá reducir el importe del pago de la multa que le correspondería o, en su caso, la sanción de carácter no pecuniario, cuando no cumpliéndose alguna de las condiciones anteriores, el denunciante facilite elementos de prueba que aporten un valor añadido significativo respecto de aquellos de los que se disponga. En ambos casos, será necesario que el denunciante cese en la 
participación de la infracción y no haya destruido elementos de prueba relacionados con el objeto de la denuncia. La novedad es la regulación con alcance general, pues la figura ya existía en el ámbito de la defensa de la competencia [art. 65.1.a) de la Ley 15/2007, de 3 de julio, «con la exención del pago de la multa impuesta cuando sea la primera en aportar elementos de prueba que, a juicio de la Comisión Nacional de la Competencia, le permitan ordenar el desarrollo de una inspección en relación con un cártel»]. En el ámbito penal, al arrepentido que presta esta colaboración activa se le premia con la imposición de una pena inferior en uno o dos grados, siquiera sea solo en los casos en que el delito es de menor gravedad existiendo el atenuante de confesión (art. 21.4. ${ }^{\circ} \mathrm{CP}$ ). En definitiva, estas declaraciones incriminatorias tienen sus reglas de contraste con la presunción de inocencia establecida que relativizan su valor probatorio [así, la STC 233/2002, de 9 de diciembre; y las SSTC 68/2001 (Secuestro de Segundo Marey); 2/2002 (coimputados y derecho al silencio); 68/2002 (coimputados y testigos de referencia); 65/2003 (los coimputados no corroboran a otros coimputados); 17/2004 (coimputado rebelde); 30/2005 (declaración de menor coimputado)] que ha sido objeto de profundo análisis por SÁNCHEZ YLLERA ${ }^{23}$.

\section{B. Legitimación colectiva en manos de las asociaciones}

Por tanto, en contenciosos ambientales los problemas mayormente se plantean respecto de los recurrentes personas físicas (la STS de 22 de abril de 2002, Sala Tercera, de lo Contencioso-administrativo, Sección 4 ${ }^{\text {a }}$, Rec. 3799/1997, Ponente XIOL RÍOS, LA LEY 6202/2002, f. de Dcho $11^{\circ}$. La impugnación individual por los ciudadanos de actos administrativos que afecten al medio ambiente no está habilitada, como se ha visto, por el reconocimiento de una acción popular"). Obviamente, la LJCA sigue operando en contenciosos ambientales reconociéndose legitimación con fundamento en la existencia de intereses legítimos colectivos y sigue aplicando para ellos doctrinas jurisprudenciales previas a Arhus y la ley 26/2007. Antes de la Ley 26/2007, la STS de 24 de diciembre de 2001, Sala Tercera, de lo Contencioso-administrativo, Sección 5a, Sentencia Rec. 347/1999, Ponente ENRÍQUEZ SANCHO, LA LEY 233252/2001, F. de Dcho $2^{\circ}$ reconoció legitimación activa a Ecologistas en Acción-CODA y Greenpeace-España en la sustanciación de un recurso referente a la autorización de un almacén de residuos radiactivos, afirmando que "Las asociaciones recurrentes gozan de la legitimación que les reconoce el artículo 19.1.b) LJ, e, independientemente de ello, de la que les otorga el artículo 304 LS, aplicable también cuando se trata de impugnar acuerdos del Consejo de Ministros adoptados conforme a lo previsto en el artículo 244.2 de esta Ley",

23 SÁNCHEZ YLLERA, I., «Dudas razonables: la declaración de los coimputados», Revista Xurídica Galega, n. ${ }^{\circ}$ 50, 2006 pp. 13-33. 
Después de la Ley 27/2006, la jurisprudencia del TS, ya con el viento a favor de la Convención de Arhus y la propia Ley 27/2006, se ha reconocido legitimación a asociaciones ambientalistas. Son buen ejemplo de ello las STS de 15 de septiembre de 2009, Rec. 151/2007, Sala Tercera, de lo Contencioso-administrativo, Sección $3^{\text {a }}$, Ponente BANDRÉS SÁNCHEZ-CRUZAT, LA LEY 184140/2009, f. de Dcho $2^{\mathbf{o}}$; STS de 31 de marzo de 2009, Sala Tercera, de lo Contencioso-administrativo, Sección $3^{\text {a }}$, Rec. 5119/2006, Ponente BANDRÉS SANGHEZ-CRUZAT, LA LEY 75486/2009, f. de Dcho $5^{\circ}$ - legitimación de la Asociación plataforma en defensa da ría de Arousa-, y la STS de 17 de mayo de 2011, Sala Tercera, de lo Contencioso-ad-

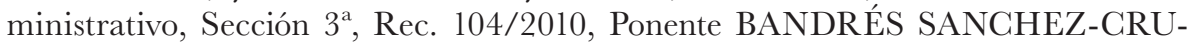
ZAT, LA LEY 62895/2011, f. de Dcho $2^{\circ}$, que reconoce legitimación activa a la Agrupación de vecinos y amigos de Llanes-Avall -usando el propio art. 45 CE y afirmando que dicho precepto "promueve que todos tengan el derecho a exigir a los poderes públicos que adopten las medidas necesarias para garantizar la adecuada protección del medio ambiente.”- ${ }^{24}$.

Así lo hace también la STS de 7 de febrero de 2011 (Sala de lo Contencioso-Administrativo, Sección 5a), RJ 2011 \610, recurso de Casación 599/2007, Ponente CALVO ROJAS, f. de Dcho $3^{\circ}$, respaldando la legitimación basándose en tres argumentos que subscribe de la sentencia de instancia: 1) los Estatutos de la referida asociación establecen como fines, entre otros, los previstos en el artículo 3 .e/ consistente en personarse como parte interesada participando vía jurídica o administrativa, así como promover o realizar actos reivindicativos en todos los proyectos que afecten tanto al medio ambiente como a la conservación y defensa de la naturaleza; 2) y que dicha Asociación recurrente en alzada en ningún momento fue requerida por la Administración para que justificase acuerdo de la Asociación en orden a facultarla para la interposición del recurso en nombre de la Asociación 3·) Además, la sentencia de instancia destaca también que no cabe cuestionar en vía judicial la legitimación de quien recurrió en alzada sin ser cuestionada entonces la legitimación ${ }^{25}$. La STS de 28 diciembre 2011 (Sala de lo Contencioso-Administrativo, Sección 3ª),

$24 \quad$ Así también, la STS de 29 de noviembre de 2006, Sala Tercera, de lo Contencioso-administrativo, Sección 5a, Rec. 933/2003, Ponente FERNÁNDEZ VALVERDE, LA LEY 209629/2006 -legitimación de la Asociación para la defensa del desarrollo ecológico sostenible ex art. 19.1.b y 18.2 LJCA interpretados a la luz de la Ley 26/2007 y el Convenio Arhus-.

25 En este sentido, también la STS de 19 de enero de 2000 (Sala de lo Contencioso-Administrativo, Sección $3^{\mathrm{a}}$ ), Recurso contencioso-administrativo 243/1998, Ponente GONZÁLEZ GONZÁLEZ, RJ $\backslash 2000 \backslash 20$, admitiendo la legitimación de la Confederación Sindical de Comisiones Obreras para impugnar el Real Decreto 782/1998, de 30 abril, por el que se aprueba el Reglamento para desarrollar la Ley 11/1997, de 24 abril, de Envases y Residuos de Envases, pues "durante la tramitación del procedimiento de elaboración de la norma impugnada, la Administración dio intervención a la parte recurrente, lo que supone su legitimación para recurrir, como hay que inferir del artículo 31.1 c) de la Ley de Procedimiento Administrativo Común. 
recurso de Casación 4560/2007, Ponente ESPÍN TEMPLADO, RJ 2012\460, ha reconocido legitimación activa a una sociedad de cazadores para impugnar la constitución de un coto privado de caza, pues las sociedades de cazadores tienen reconocida por la legislación estatal y autonómica una función colaboradoras en la protección de la fauna silvestre y en la gestión de la caza. También la STS de 8 de junio de 2015 (Sala de lo Contencioso-Administrativo, Sección 6 ${ }^{\text {a }}$, Recurso de Casación 39/2014, Ponente DEL RIEGO VALLEDOR, RJ 2015 3166 , f. de Dcho $3^{\circ}$, ha apreciado existente la legitimación activa de la Asociación Ecologistas en Acción-CODA para la impugnación de un indulto concedido a condenado por delito medio ambiental estimando presente un interés difuso en la protección del medio ambiente siendo indiferente su falta de personación en el proceso penal seguido por el delito contra el medio ambiente, pues esa falta de personación en vía penal "en nada perjudica ni afecta a los fines de tutela del medio ambiente encomendados a la asociación recurrente por la ley, que pueden actuarse, indistintamente, bien en la persecución de actuaciones contra la ordenación del territorio que puedan ser constitutivas de delito bien en la oposición al perdón de la pena impuesta por un delito de esa naturaleza con infracción o al margen de los requisitos establecidos por la ley".

Debemos resaltar en este sentido la importante STS 1188/2017 de 7 de Julio de 2017, rec.1783/2015, Sala Tercera, de lo Contencioso-administrativo, Sección $3^{\text {a }}$, Ponente AROZAMENA LASO, LA LEY 121319/2017, asunto "Fundación Oceana" ${ }^{26}$. La sentencia declara la legitimación de la Fundación Oceana para ser parte en el expediente promovido contra dos buques por infracción consistente en vertidos contaminantes. Tiene la condición de persona interesada. Ostenta un especial interés legítimo colectivo teniendo en cuenta la significación constitucional del medio ambiente y el principio de efectividad del Derecho ambiental ${ }^{27}$. Al personarse en el procedimiento sancionador no actuó movida, exclusivamente, por la defensa de la legalidad, sino por la defensa del medio ambiente marino y por su interés en que sea protegido eficazmente. Además, dicha Fundación está legitimada para ejercer la acción popular en materia medioambiental, dado que cumple los requisitos del art.

26 Analizada por CASADO CASADO, L. "Sentencia del Tribunal Supremo de 7 de julio de 2017 (Sala de lo Contencioso-Administrativo, Sección 3", Ponente Ángel Ramón Arozamena Laso)", Actualidad Jurídica Ambiental, No 73 (Noviembre), 2017, pp. 69-74.

27 Esta línea jurisprudencial al amparo del art. 19 LJCA había sido anticipada por la STS de 25 de junio de 2008 (caso de la construcción del aeropuerto de Castellón), a la que siguen, entre otras, la STS de 1 de diciembre de 2009, la STS de 25 de mayo de 2010 y las sentencias del Tribunal Superior de Justicia de Madrid de 17 de diciembre de 2009 y de 21 de junio de 2010 (véanse SALAZAR ORTUÑO, "El desarrollo del Convenio de Aarhus y la progresiva desaparición de obstáculos para el acceso a la justicia ambiental: reconocimiento en la jurisprudencia del Tribunal Supremo de la legitimación activa a las organizaciones no gubernamentales que trabajan a favor de la protección del ambiente", Revista Aranzadi de derecho ambiental, $n^{\circ}$. 17, 2010, pp. 191-202 y ORTEGA BERNARDO, J. (2011: 4-5). 
23 de la Ley 27/2006, y no tiene sentido que si esta Ley le permite impugnar una resolución administrativa que culmina un procedimiento sancionador por vulnerar la legislación medioambiental, no le permita que sea parte en el procedimiento en el que se ventila ese asunto.

\section{Legitimación de los Ayuntamientos y partidos políticos}

Varios pronunciamientos han venido a respaldar la legitimación de los Ayuntamientos para actuar ante la jurisdicción en defensa del medio ambiente. Destacamos la STS de 20 de septiembre de 2004, Rec. 2874/2001, Sala Tercera, de lo Contencioso-administrativo, Sección $3^{\mathrm{a}}$, Ponente TRUJILLO MAMELY, LA LEY 2190/2004, f. de Dcho 6, ${ }^{\mathbf{o}}$ que respalda la legitimación activa del Ayuntamiento para impugnar el acto, aunque la línea eléctrica no esté situada en su territorio, al estar interconectados los puntos eléctricos y depender unos de otros, teniendo interés indirecto o difuso ${ }^{28}$. El precedente es muy importante porque rompe con la idea de afectación territorial que en materia de medio ambiente no debiera existir. La muerte de un oso en Asturias nos afecta a todos. En un ecosistema planetario interconectado, ciertamente tiene poco sentido hablar de ámbitos territoriales afectados.

La STS de 7 de diciembre de 2011, rec. 377/2008, Sala Tercera, de lo Contencioso-administrativo, Sección 5a, Ponente RODRÍGUEZ-ZAPATA PÉREZ, LA LEY 241514/2011, ha reconocido legitimación activa en materia ambiental a los Ayuntamientos -consolidando esto como jurisprudencia ${ }^{29}$ - cuando actúan en defensa de sujetos lesionados en sus derechos en materia ambiental. Para el TS la sentencia recurrida había reconocido correctamente la legitimación del Ayuntamiento de Gavà, conforme a la Ley 37/2003, de 17 de noviembre, del ruido. El Abogado del Estado, oponía en su contrarrecurso, que el Ayuntamiento de Gavà no era titular de los derechos fundamentales invocados. Esta objeción no debe prosperar según el TS porque no se trata de invocar derechos fundamentales ajenos en su dimensión de normas de derechos subjetivos (Cfr., STC 26/2011, de 14 de

${ }_{28} \quad$ Literalmente: "En este caso, aunque la línea eléctrica cuya autorización y declaración de utilidad pública se ha otorgado no está situada en punto alguno del término municipal de la Corporación Local recurrente en la instancia, y por más que se trate de una red de transporte interconectada de suerte que todos los elementos y puntos que la componen o están relacionados o dependen de los demás, puesto que la energía que se consume o transforma en un punto concreto puede proceder de otro físicamente muy alejado, no por eso deja de estar más directamente afectado el Ayuntamiento recurrente en cuanto al establecimiento, modificación o alteración en las líneas de transporte energético de llegada y salida a una subestación radicada en un barrio de dicho municipio. Se trata, si se quiere, de un interés indirecto o difuso, pero en todo caso susceptible de la protección a cuya satisfacción sirve el proceso.".

29 La reconoce previamente la sentencia del Tribunal Supremo de 27 de abril de 2004, que confirma sentencia del Tribunal Superior de Justicia de Cataluña de 21 de octubre de 1999, dictada en un recurso formulado al amparo de la Ley 62/1978 (LA LEY 2486/1978). 
marzo (LA LEY 6062/2011), f.j. núm. 3), sino en su dimensión objetiva de normas esenciales del ordenamiento jurídico constitucional, dada la naturaleza dual de las normas que consagran derechos fundamentales en nuestra Constitución (por todas, STG 196/2006, de 3 de julio (LA LEY 74122/2006), f.j. núm. 6), para lo que no se puede negar legitimación al Ayuntamiento, una vez reconocido su ámbito competencial.

Mas restrictivo ha sido el TS respecto de los partidos políticos. La STS de 25 de junio de 2014, Sala Tercera, de lo Contencioso-administrativo, Sección 3 ${ }^{\text {a }}$, rec. 365/2012, Ponente PERELLÓ DOMÉNECH, LA LEY 74650/2014, respecto de la impugnación del Real Decreto 547/2012 de 16 marzo, por el que se convalida el Real Decreto 1462/2001, por el que se otorgan los permisos de investigación de hidrocarburos ha declarado que no es suficiente su condición de organización o partido político a efectos de reconocerle legitimación para recurrir el Real Decreto impugnado ${ }^{30}$.

D. La restrictiva legitimación del Ministerio Fiscal

La STS de 28 de noviembre de 2014, Sala Tercera, de lo Contencioso-administrativo, Sección 5 ${ }^{\mathrm{a}}$, Sentencia, Rec. 3756/2012, Ponente SUAY RINCÓN, LA LEY 176906/2014, ha reducido el ámbito de legitimación del Ministerio Fiscal de conformidad con las previsiones de la LJCA y la LRM.

El TS estima inaplicable la cláusula del interés legítimo prevista en el art. 19.1 a) LJCA, aplicando la cláusula recogida en el ap. f) del mismo artículo, dedicada específicamente al Ministerio Fiscal, por medio de la cual tiene reconocida legitimación para actuar en el ámbito de la jurisdicción contencioso-administrativa, pudiendo intervenir en los procesos que determine la Ley. El TS entiende limitada su legitimación, conforme a la disposición adicional 8. ${ }^{a}$ de la Ley 26/2007, de responsabilidad medioambiental, a los procesos que se desarrollen en el ámbito de aplicación de esta Ley, que se proyecta sobre los daños ambientales y sobre las amenazas inminentes de que tales daños ocurran. La consecuencia es que se declara inamisible el recurso interpuesto por el Ministerio Fiscal contra la desestimación presunta por silencio de la Consellería de Medio Ambient, Aigua, Urbanismo, i Habitatge de su solicitud de revocación de la autorización administrativa otorgada para la construcción del Parque Eólico en la Zona 12 (Enguera).

$30 \quad$ F. de Dcho $5^{\circ}$ : "El que los partidos sean el cauce de la participación política, y concurran a la formación de la voluntad popular, no es suficiente para conferirles legitimación para la impugnación de cualquier actividad administrativa, si no se aprecia una conexión específica con un concreto interés, actuación o funcionamiento del partido". 


\section{La apertura de la casación por grave daño a los intereses generales.}

La última reforma de casación suprimiendo el recurso de casación en interés de ley ha producido una apertura de legitimación en la fase casacional. En efecto, la casación en interés de ley era patrimonio exclusivo de la Administración. Esto ha cambiado. Recordemos que concurre «interés casacional objetivo para la formación de la jurisprudencia", del artículo 88.2, apartado b) "Siente una doctrina sobre dichas normas que pueda ser gravemente dañosa para los intereses generales". GUERRERO ZAPLANA Magistrado Especialista en lo Contencioso Administrativo de la Audiencia Nacional, ha sostenido que ya no juega la limitación en cuanto a la legitimación que procedía de la regulación del anterior recurso de casación en interés de ley, y cualquier persona que considere que la sentencia dictada en primera instancia o apelación incorpora una doctrina gravemente dañosa para los intereses generales podrá fundar su recurso en este supuesto del artículo 88.2.b LRJCA ${ }^{31}$. Este criterio de legitimación permitiendo invocar a sociedad mercantil el art. 88.2.b LRJCA, es expresado por la Sala de Admisión en el Auto de 12 de febrero de 2018, Rec. 5994/2017, Sala Tercera, de lo Contencioso-administrativo, Sección 1 1a, Ponente FRÍAS PONCE), LA LEY 2371/2018 o por el Auto de 23 de febrero de 2018, Rec. 6379/2017, Sala Tercera, de lo Contencioso-administrativo, Sección 1a, Ponente HUERTA GARICANO, LA LEY 4151/2018 ECLI: ES:TS:2018:1556. Y de modo expreso, por el Auto de 27 de marzo de 2017, Rec. 263/2017, Tribunal Supremo, Sala Tercera, de lo Contencioso-administrativo, Sección $1^{\text {a }}$, Ponente SUAY RINCÓN, LA LEY 17346/2017 ECLI: ES:TS:2017: 2674a , R.J 3, al afirmar que "No cabe considerar que corresponde en exclusiva a la Administración la defensa de los intereses públicos y los medioambientales forman parte sin dudas de ningún género de tales intereses".

\section{MEDIDAS CAUTELARES}

La protección del medio ambiente se ha incorporado a nuestro ordenamiento constituyendo un importante condicionante en la realización de obras y proyectos públicos. La suspensión de la ejecución de un proyecto público puede ser una consecuencia directa impuesta por la legislación ambiental. En el derecho básico estatal, la suspensión o paralización administrativa de proyectos y obras está contemplada en determinadas circunstancias por la legislación de evaluación de impacto ambiental y por la legislación en materia de conservación de la naturaleza.

31 "La nueva casación contenciosa administrativa. Primeros pronunciamientos de la sala de admisión”, Revista Furídica de Castilla y León, N. ㄴ 44. Enero 2018, pp. 66-67. 


\section{Medio ambiente y tutela cautelar ${ }^{32}$}

La fundamentación última del artículo 130 LRJCA hunde sus raíces en el derecho fundamental consagrado en el artículo $24 \mathrm{CE}$ del que deriva la potestad jurisdiccional para adoptar medidas cautelares. De este modo, la efectividad que se predica de la tutela judicial respecto de cualesquiera derechos o intereses legítimos, reclama la posibilidad de acordar las adecuadas medidas cautelares que aseguren la eficacia real del pronunciamiento futuro que recaiga en el proceso (STC 148/1993, de 29 de abril, f.j. núm. 4).

La razón determinante para acceder o no a la suspensión de la ejecución del acto o disposición objeto de impugnación en vía jurisdiccional se encuentra en la necesidad de evitar que la eficacia de la disposición o la ejecución del acto administrativo pueda hacer perder al proceso su finalidad legítima, como dispone el artículo 130.1 LJCA. Si bien, el propio precepto impone una previa valoración circunstanciada de los intereses en conflicto, para denegar la medida cautelar si de ésta pudiera seguirse perturbación grave de los intereses generales o de terceros.

\section{Obligatoriedad ex artículo $45 \mathrm{CE}$ de adopción de medidas cautelares por la existencia de perjuicios de imposible reparación para el medio ambiente. La prevalencia de los intereses generales (protección medioambiental) frente a los intereses particulares o intereses de tercero.}

La jurisprudencia de nuestro TS ha consolidado como importante línea jurisprudencial la prevalencia del interés público en la preservación del medio ambiente. De este modo, la protección del medio ambiente legalmente determinada es un interés público prevalente determinante de la suspensión de la eficacia de los actos que inciden desfavorablemente sobre el ambiente ${ }^{33}$. El elemento decisivo para el otorgamiento de

32 Nos basamos en este caso en nuestro previo estudio El proceso de afirmación del medio ambiente como interés público prevalente o la tutela cautelar ambiental efectiva: La suspensión de los actos administrativos por razón de la protección del medio ambiente en la jurisprudencia del TS, "Revista de administración pública”, ISSN 0034-7639, N 145, 1998, pp. 169-198, que actualizamos en jurisprudencia al que nos remitimos in totum sin perjuicio de su reproducción parcial aquí.

33 Obviamente en materia de tutela cautelar el casuismo es la regla. Pues la ponderación de intereses debe realizarse caso por caso. Así, por ejemplo, la STS 2651/2016 de 16 Dic. 2016,Tribunal Supremo, Sala Tercera, de lo Contencioso-administrativo, Sección 5a, Rec. 672/2016, Ponente PECES MORATE, LA LEY 193624/2016, acuerda la suspensión cautelar del acuerdo que inicia el procedimiento para la ampliación del Espacio Protegido Red Natura 2000 Laguna de Hito y la modificación del Plan de Ordenación de los Recursos Naturales de la Reserva Natural de la Laguna del Hito, afectando al emplazamiento del proyectado Almacén Temporal Centralizado nuclear de Villar de Cañas. En la ponderación de los intereses en conflicto se declara la prevalencia del interés público en una adecuada gestión de los residuos radioactivos para mejorar la seguridad nuclear frente a la ampliación inmediata de un espacio protegido para las aves y la modificación de un PORN. 
la suspensión de un acto o disposición presuntamente atentatorio al medio ó del mantenimiento de la eficacia de un acto protector es la existencia de afección. Si existe tal afección, el artículo $45 \mathrm{CE}$, en cuanto principio rector que informa la práctica judicial, hace obligada la suspensión del acto administrativo o disposición susceptible de causar perjuicios de difícil reparación al medio ambiente como bien jurídico constitucionalmente protegido. El ATS de 17-2-1990, Ar. 1439 ( Sala 3 3 , Sección 5a , Ponente, GONZÁLEZ NAVARRO) es una muestra de esta doctrina jurisprudencia en su génesis. El elemento decisivo para el otorgamiento de la suspensión es la existencia de afección al medio. Si existe tal afección, el artículo $45 \mathrm{CE}$ hace obligada la suspensión del acto administrativo susceptible de causar perjuicios de difícil reparación al medio ambiente como bien jurídico constitucionalmente protegido. Esta es la síntesis extraíble de los Fundamentos de Derecho $2^{\circ}, 3^{\circ}$ y $4^{\circ}$ que transcribimos a continuación.

SEGUNDO.- Establecido lo anterior, lo que hay que tener presente es que si se ejecuta la obra de cuya autorización aquí se trata y luego resultara que no procede su realización el perjuicio causado al medio ambiente sería, por lo menos, de muy difícil reparación, y en ello coincide también el Abogado del Estado.

TERCERO.- Porque se trata de construir un vertedero controlado de residuos- de cuyo volumen e importancia da idea el que el coste previsto es de más de ciento sesenta millones de pesetas- en el Monte Teixeiro. Y es claro que esa obra exige arrasar -así literalmente- una parte de dicho Monte, con todo lo que ello supone de quebrantamiento de la delicada armonía de la naturaleza. Subrayar esto es importante para poner de relieve que restaurar las cosas a su primitivo estado, si esa obra, una vez realizada, se declarara no ajustada a derecho, es en este caso muy difícil, por no decir imposible, que exige mucho tiempo, además, y sin que baste con una indemnización sustitutoria para reparar el daño causado.

CUARTO.- En la defensa del medio humano -uno de los más preocupantes problemas que se plantean hoy día- los poderes públicos tienen marcado muy claramente la conducta a seguir; protección y defensa de aquél. Y ello no sólo por sentido común, que no sería argumento desdeñable, sino porque la propia Constitución española de 27 de diciembre de 1978 (RCL 1978\2836 y ApNDL 197585, 2875), en su importe art. 45.2 les impone el deber de velar por una utilización racional de los recursos naturales. Obviamente ese deber constitucional alcanza no sólo a la Administración pública sino también a los Tribunales.

Otro ejemplo de la prevalencia del interés ambiental es el Auto de 7-11-1995, Ar. 8134 (Sala 3 $3^{\text {a }}$, Sección 6 ${ }^{\text {a }}$, Ponente, MATEOS GARCíA) ${ }^{34}$. Este Auto tiene el

34 En esta ocasión, el recurso de apelación, interpuesto contra el Auto de la Sección Primera de la Sala de lo contencioso-administrativo del TSJ de Madrid, de fecha 14 noviembre 1991, por el que se resolvió denegar la solicitada suspensión del acuerdo del Consejo de Gobierno de la Comunidad Autónoma de Madrid, declarando de urgencia la ocupación de los bienes y derechos que integran "El Carrizal de Villamejor", en el término municipal de Aranjuez. El recurrente estimaba que los Decretos 97/1990, de 
interés de aplicar la doctrina de la prevalencia en armonía con las nuevas doctrinas y reinterpretaciones del entonces vigente art. 122 LJCA ex art. 24 CE. Y se considera que la mera presencia de especies protegidas por sí misma puede "tener un impacto considerable por su naturaleza, existiendo el riesgo de que transforme de manera importante o irreversible factores medioambientales, con independencia de sus dimensiones." Así, Sentencia Tribunal Superior de Justicia las Islas Canarias, Las Palmas, núm. 139/2010 (Sala de lo Contencioso-Administrativo, Sección 2a), de 16 de julio, Ponente RODRÍGUEZ FALGÓN, JUR 2011 \7215, f. de Dcho $3^{\circ}$. Es ejemplar en este sentido la Tribunal Supremo, Sala Tercera, de lo Contencioso-administrativo, Sección 5a, Sentencia de 20 de 20 de febrero de 2013, Rec. 544/2012, Ponente PECES MORATE, LA LEY 16023/2013, en relación con la impugnación del auto por el que se acordó la medida cautelar de suspender la ejecución de la Orden del Ministerio de Medio Ambiente, referida a la autorización de ejecución por emergencia de obras para la conducción del abastecimiento de agua desde un embalse. El TS declara que la ejecución de la Orden puede hacer perder su finalidad legítima al recurso interpuesto contra ella por dos motivos; uno de carácter jurídico, pues a pesar de haberse declarado nulo de pleno derecho el Real Decreto que le da amparo, la Orden impugnada sigue vigente en el ordenamiento jurídico con vocación de producir efectos y otro de naturaleza física y ambiental, dado que la conducción del abastecimiento desde el embalse, conlleva una mutación del entorno con afectación a la flora y fauna del paraje, con la consiguiente incidencia en el medio y un gran impacto ambiental. No se considera prevalente el pretendido interés general de abastecer de agua a una población, porque se compadece mal con el prolongado tiempo de realización de las obras durante cinco años, sin que la urgencia aparezca justificada en circunstancias de sequía o ciclos hídricos, que se desconoce si subsisten en la actualidad o si subsisten con la intensidad suficiente para justificar la inmediata ejecución de las obras varios años después de aprobadas, frente a los referidos perjuicios ambientales.

Se configura así como sólido criterio jurisprudencial que el interés público medio ambiental ha de ser considerado prevalente en relación, por ejemplo, con el desarrollo urbanístico, desde el Auto de 11 de mayo de 1989. Así, el interés público demanda una protección eficaz del medio ambiente lo que incluye los valores paisajísticos -Auto de 15 de septiembre 2009, Tribunal Supremo (Sala de lo Contencioso-Administrativo, Sección 5ª, JUR 2009\423777, f. de Dcho 2; STS (Sala de lo Contencioso-Administrativo, Sección $5^{\circ}$ ) de 29 enero de 2010, RJ 2010/1137, f. de Dcho 5 STS (Sala de lo Contencioso-Administrativo, Sección 5a) de 21 de octubre de 2010, RJ 2010 77513,

5 diciembre y 21/1991, de 21 marzo, por los que, respectivamente, se sometió el mencionado "Carrizal" a un régimen de protección preventiva y se declaró reserva natural, incidían en nulidad de pleno Derecho y que el auto apelado ni recogía el principio del "fumus boni iuris", favorable al otorgamiento de la suspensión interesada, ni la nueva orientación jurisprudencial. 
Ponente FERNÁNDEZ VALVERDE, f. de Dcho 8 -la prevalencia de los intereses generales (que se concentran en la protección medioambiental expresada) frente a los intereses particulares o intereses de tercero-.

Este, no podría ser otro modo, es el criterio expresado por el TSJ de Andalucía, por ejemplo, en la STSJ Sala de Sevilla (Sala de lo Contencioso administrativo, Sección $2^{\text {a }}$ ) en Sentencia de 12 febrero de 2008, JUR 2008\113144, f. de Dcho $3^{\circ}$, que transcribimos:

TERCERO:" ..........Y en el presente caso, es evidente que frente al interés de la actora de mantener abierta la actividad, existe un interés general de los poderes públicos, que así por cierto le viene ordenado por la propia Constitución, $\operatorname{art}^{\circ} 45$ de la GE, como es el mantenimiento de un medio ambiente adecuado a las necesidades colectivas y a mantener el equilibrio entre actividades que pueden afectar al medio ambiente y el respeto a este, medio ambiente que en la actualidad, por lo que de deterioro generalizado se está produciendo, que forma parte de las prioridades generales públicas, y otro evidente particular de los propios usuarios de la actividad de garantizarle su seguridad. Por tanto, intereses generales por un lado y de terceros, que por su valor intrínseco como se ha dejado dicho, han de prevalecer respecto de los de la actora que alega perjuicios económicos y pérdida de los empleos. Lo que también por esta vía hemos de mantener el auto recurrido.

Por lo demás, la alegación del art $^{\circ} 111$ de la Ley 30/92, es evidente que no puede ser objeto de la presente pieza, en tanto que se corresponde con ámbitos competenciales distintos, y ello sin perjuicio de que el silencio de dicha petición en vía administrativa pueda ser objeto del correspondiente control judicial".

Este criterio es también el mantenido en el Tribunal Superior de Justicia de Andalucía, en múltiples sentencias entre las que citamos las siguientes: STSJ Andalucía, Sevilla, (Sala de lo Contencioso-Administrativo, Sección 3 ${ }^{\mathrm{a}}$ ) de 10 de enero de 2001, JUR 2001\162039, -la protección, aún provisional, del medio ambiente es interés preponderante frente a los intereses meramente económicos que se adivinan en las alegaciones de la parte actora- f. de Dcho $3^{\circ}$; STSJ de 4 septiembre de 2007, JUR 2008\61008, f. de Dcho 3; STSJ de 15 julio de 2008, JUR 2009\85173, f. de Dcho $3^{\circ}$.

\section{A MODO DE CONCLUSIÓN}

Quizá el mayor problema de la Ley 27/2006 estudiada es la parquedad en la regulación y la escasa ambición normativa de los postulados. En este sentido debe resaltarse el problema que se genera al no establecerse una regulación expresa sobre las fianzas y cauciones en medidas cautelares. Este problema debiera haber sido 
resuelto. En los contenciosos ambientales este es el momento crucial y decisivo pues ningún juez va a ordenar la demolición de lo ya construido o ejecutado. Cuando se han otorgado medidas cautelares éstas han sido inviables por la exigencia de fianzas desorbitadas (miles de millones de las antiguas pesetas en el caso de Itoiz). La Ley $27 / 2006$ no da una respuesta clara y adecuada a este problema porque reenvía a la Ley 1/1996 de 10 de enero de asistencia jurídica gratuita. O el mismo art. 20 3 LOPJ. Pues bien, el status quaestionis actual es el que sigue. Se interpreta que la justicia gratuita no alcanza las fianzas (SAP de Cantabria de 9 de enero de 2004 y SAP de Cádiz de 8 de enero de 2002). Tampoco la fianza de ejecución provisional -STS de 7 de mayo de 2002, RJ 6524-. La única piedra de toque en este panorama desolador es la STC 2002/45, de 25 de febrero que reputa contraria al art. 24 CE una fianza desproporcionada habida cuenta las circunstancias del caso y existencia del beneficio de justicia gratuita. Esta es la vía obligada en tanto no se reforme la Ley -que debiera serlo-. Los artículos 9 aparatados 4 y 5 y 3.8 del Convenio de Arhus imponen la proporcionalidad de los costes. Muy positiva nos parece en sentido la STSJ de valencia de 12 de mayo de 2005 al afirmar la existencia de responsabilidad patrimonial de la Administración Pública ex arts. 139 y ss de la Ley 30/1992 (hoy arts. 32 y ss de la Ley 40/15 de Régimen Jurídico del Sector Público), cuando prospera el ejercicio de una acción contra la actuación ilegal de la Administración. Es una vía para la recuperación de costes e indemnización de los perjuicios producidos por la Administración en el empecinamiento en una actuación ilegal. Esta responsabilidad debiera ser pedida y reconocida en los procesos en que se ejercite una acción popular para no avocar a un nuevo proceso resarcitorio terminado el principal.

Otra importante cuestión es si el régimen establecido por la Ley 27/2006, de 18 de julio supone una derogación de la legitimación existente. Y la legitimación existente, como hemos visto, puede ser más favorable si existen acciones populares verdaderas. La respuesta ya anticipada es que no. A esta solución se llega por la consideración de las normas que la reconozcan como lex specialis de prevalente aplicación. Habrá que recordar que en Italia después de 1986, mediante la legge n. 349 por la se creó el Ministerio de Medio ambiente, se estableció un régimen de asociaciones individuadas por decreto del Ministerio que cumplieran determinados requisitos y allí la jurisprudencia ha reconocido con posterioridad legitimación a asociaciones no individuadas ${ }^{35}$. Por eso, tanto si existen acciones populares como otras formas de legitimación general previstas en la Ley 29/1998, entendemos que esas normas deben considerarse prevalentes. Otra interpretación nos llevaría al absurdo - contrario al principio pro actione y al art. $45 \mathrm{CE}$ - de haber aprobado una ley de acceso a la justicia en materia de medio ambiente para impedir y restringir dicho acceso.

35 La Protección del Derecho a un Medio ambiente adecuado, Bosch Madrid 1995, pp. 398-401. 
Se echa de menos, en cualquier caso, el establecimiento de una verdadera acción popular no contemplada en términos de posibilidad. Las leyes pueden reconocer a diestro y siniestro acciones populares pero después hace falta quienes las ejerzan. Y eso, en contenciosos ambientales es una cuestión de medios personales y materiales. Seguimos pensando que es necesario el establecimiento de programas que favorezcan la consolidación presupuestaria de actores que ejerzan como fiscales ambientales independientes exigiendo el cumplimiento de la legislación ambiental. Seguimos pensando que el problema en nuestro sistema no es la falta de legitimación sino el escaso control efectivo de la Administración en los contenciosos ambientales y la desigualdad de armas entre los intereses desarrollistas - con amplios fondos para pericias y bufetes- y los ambientalistas -sin fondos y con trabajadores en su mayoría voluntarios sin retribución-.

Creo que en contenciosos ambientales debe reconocerse en todo caso legitimación al Ministerio Fiscal. Un sistema en el que prevalece la consideración de si el Ministerio Fiscal está o no legitimado sobre el análisis de la legalidad o no de lo impugnado es un sistema enfermo. Y junto a ellos privates attonorneys. En un Estado ambiental de Derecho debe subvertirse el páramo jurídico ambiental de control jurisdiccional antes denunciado dejando atrás las normas ficción participación-control jurisdiccional posibilidad. Son necesarias normas que regulen el efectivo control con sujetos dotados de status procesal respaldado presupuestariamente.

La jurisprudencia de nuestro TS ha consolidado como importante línea jurisprudencial la prevalencia del interés público en la preservación del medio ambiente. La protección del medio ambiente legalmente determinada es un interés público prevalente determinante de la suspensión de los actos que inciden desfavorablemente, el otorgamiento de otras medidas cautelares o el mantenimiento de la eficacia de los actos favorables sobre el ambiente. El elemento decisivo para el otorgamiento de la suspensión de un acto presuntamente atentatorio al medio ó del mantenimiento de la eficacia de un acto protector es la existencia de afección. Si existe tal afección, el artículo $45 \mathrm{CE}$, en cuanto principio rector que informa la práctica judicial, hace obligada la suspensión del acto administrativo susceptible de causar perjuicios de difícil reparación al medio ambiente como bien jurídico constitucionalmente protegido. Esta doctrina, como cualquier otra en materia de suspensión ex 130 LJCA, ha experimentado inflexiones producto del conjunto de directrices generales y el extremado casuismo propio la materia. La justicia cautelar ambiental muestra la existencia de problemas propios que requieren soluciones específicas. La exigencia de caución a asociaciones ambientalistas puede determinar la impracticabilidad de adopción de medidas cautelares. Es necesaria la determinación de parámetros generales de solución. No basta la afirmación de la prevalencia. Es necesario determinar cuales son las situaciones de prevalencia y articularlas en normas-mandato hacia la justicia administrativa. Los supuestos de suspensión administrativa han de transformarse 
en normas de suspensión jurisdiccional (automáticos en determinados supuestos). Es igualmente necesario determinar cuales son los parámetros generales de prueba de la afección al medio ambiente y regular la carga de la prueba -que debiera descansar sobre el que niegue la afección-. El principio de cautela inserto en el artículo 191 TFUE ha de constituir un reforzante en el favorecimiento de la suspensión. En este campo existen propuestas que debieran ser consideradas por el Legislador ambiental; en concreto, la introducción de un plazo a los efectos del otorgamiento de la suspensión, un plazo obligatorio de carácter imperativo ligado a una sanción ${ }^{36}$.

36 HANICOTTE ha realizado esta propuesta en el Derecho francés sugiriendo la introducción de un plazo legal para procedimientos en los que las preocupaciones ambientales ocupen un lugar esencial (como las actividades clasificadas y los supuestos de ausencia de estudio de impacto ambiental acorde con las exigencias legales y reglamentarias, incluyendo la ausencia material o jurídica). La suspensión será una obligación para el Juez y no una simple facultad si se trata de atentados irreversibles al medio ambiente (Les sursis à exécution: point névralgique de la protection de l'environnement, Revue du droit Public", núm. 6, novembre-décembre, 1995, pp. 1597-1598). En defensa del carácter automático de la causa de suspensión, véase también, BABADJI, Le sursis à exécution pour absence d'étude d'impact: évolution et perspectives,"Revue Juridique de l’environnement", 1992, núm. 3., pp. 326-327. 


\section{BIBLIOGRAFÍA BÁSICA}

- BOYER B. \& MEIDINGER E., Privatizing regulatory enforcement: A preliminary assessment of citizen suits under federal Environmental Lawes, "Buffalo Law Review", vol 34, núm. 3, 1985, pp. 833-964.

-BREEN, B., Citizen suits for natural resources damages:Closing a gap in Federal Environmental Law, Wake Forest Law Review, vol 24, núm. 4 1989, pp. 851-880.

- CASADO CASADO, L., Sentencia del Tribunal Supremo de 7 de julio de 2017 (Sala de lo Contencioso-Administrativo, Sección 3 3, Ponente: Ángel Ramón Arozamena Laso),“Actualidad Jurídica Ambiental”, ISSN-e 1989-5666, No. 73 (Noviembre), 2017, pp. 69-74.

-GOLAÇO ANTUNES, L. F., A tutela dos interesses difusos em Direito administrativo: Para uma legitimaçao procedimental, Livraria Almedina, Coimbra 1989.

idem., Los intereses difusos:Ubicación constitucional; tutela jurisdiccionaly $<<$ acción popular de masas $>>$ (en torno a la revisión de la Constitución Portuguesa de 8 de julio de 1989), traducción por SAINZ MORENO,’R.A.P.”, núm. 124, enero-abril 1991,pp. 417-435.

-CRAMTON, R. G., Citizen suits in the environmental field- Peril or promise?, "Administrative Law Review", Spring 1973, vol. 25, núm. 2, pp. 147-156.

-FERNÁNDEZ-LOMANA GARCÍA, M., Legitimación activa de asociación: (Comentario al AAN de 22 de octubre de 2015; rec. 301/2014)" Actualidad administrativa", ISSN 1130-9946, Nº 7-8, 2016

-FERNÁNDEZ DE VELASGO R., La "acción popular" en el Derecho Administrativo, Editorial Reus S.A., Madrid 1920.

-GABA, J., M \& KELLY M. E., The citizen suit provision under CERCLA: A sheep in wolf's clothing?, "Southwestern Law Journal", special edition on environmental Law, vol 43, núm. 3, February 1990, pp. 929-955.

-GIL- ROBLES GIL-DELGADO J., La acción popular y la audiencia de los ciudadanos en el derecho ambiental, "Poder Judicial", núm. Especial IV, Consejo General de Poder Judicial, Madrid 1986, pp.167-177.

-GUERRERO ZAPLANA, J., La nueva casación contenciosa administrativa. Primeros pronunciamientos de la Sala de admisión, "REVISTA JURÍDICA DE CASTILLA Y LEÓN", N. . 44. ENERO 2018. ISSN 2254-3805, pp. 45-75.

JORDANO FRAGA, J., La Protección del derecho a un Medio Ambiente Adecuado, Ed. Bosh Barcelona 1995.

idem., El proceso de afirmación del medio ambiente como interés público prevalente o la tutela cautelar ambiental efectiva. La suspensión de los actos administrativos por razón de la protec- 
ción del medio ambiente en la jurisprudencia del TS, "Revista de administración pública", ISSN 0034-7639, Nº 145, 1998, pp. 169-198.

idem., Análisis de la Ley 27/2006 en cuanto al acceso a la justicia, en especial el principio de legitimación en los contenciosos ambientales, "Estudios de derecho judicial", ISSN 1137-3520, N 137, 2007 (Ejemplar dedicado a: Examen del a nueva Ley de acceso a la información, participación pública y acceso a la justicia en materia de medioambiente) pp. 115-140.

- LOPERENA ROTA, Demetrio \& BALlESTEROS PINILLA, G. A., El ejercicio de acciones en el orden contencioso-administrativo en defensa del medio ambiente "Revista jurídica de Castilla y León”, ISSN 1696-6759, N. 26, 2012 (Ejemplar dedicado a: Control judicial de las Administraciones Públicas), pp. 177-210

- MARTÍ DEL MORAL, A.J., La legitimación ambiental por intereses colectivos en la jurisdicción contencioso-administrativo en Intereses colectivos y legitimación activa / Eloísa Carbonell Porras (dir.), Rafael Cabrera Mercado (comp.), 2014, ISBN 978-84-9059590-9, pp. 411-434.

- MARTÍN MATEO, R., La problemática asimilación del acccionariado popular, “R.E.V.L.”, núm. 179, julio-agosto -septiembre, 1973, pp. 471-485.

- ORTEGA BERNARDO, J., Quién ha apostado por la efectiva implantación del derecho de acceso a la justicia a favor de las organizaciones no gubernamentales en defensa del medio ambiente?", “Actualidad Jurídica Ambiental”, ISSN-e 1989-5666, Nº 6 (Octubre), 2011, pp. 10-23.

- PÉREZ CONEJO, L., La defensa judicial de los intereses ambientales: (estudio especifico de la legitimación "difusa" en el proceso contencioso-administrativo), Lex Nova, 2002. ISBN 84-8406-470-0.

- PÉREZ MORENO, A., La acción popular en materia de urbanismo, "R.D.U." núm. 15, octubre-noviembre-diciembre 1969, pp. 71 a 98.

- PEÑALVER i CABRÉ. A., Les pretensions davant la inactivitat administrativa en materia sancionadora ambiental, Tirant, Valencia 2004.

idem., Nuevas tendencias sobre la inactividad administrativa en la aplicación de las sanciones ambientales, "Cuadernos de derecho local", ISSN 1696-0955, Número 7, 2005, pp. 173-185.

- PONS PORTELLA, M., La acción popular medioambiental en el control jurisdiccional de la gracia de indulto: el caso del Real Decreto 863/2013, “Actualidad Jurídica Ambiental”, ISSN-e 1989-5666, Nº 62 (Noviembre), 2016, pp. 7-33. 
- RAZQUÍN LIZARRAGA, J. A. \& RUIZ DE APODACA, Á., Información, Participación y Fusticia en materia de Medio ambiente, Thomson-Aranzadi, Cizu Menor Navarra 2007.

- REGO BLANCO, M ${ }^{a}$ D., La acción popular en derecho administrativo y en especial, en el derecho urbanistico IAAP, Sevilla 2005.

idem., Ante la inactividad local, ¿sustitución, acción popular o contencioso interadministrativo? Reflexiones a propósito de la protección de la legalidad urbanística, "REALA" núm. 300-301, enero-agosto 2006, pp. 541-563.

- SALAZAR ORTUÑO, E., El desarrollo del Convenio de Aarhus y la progresiva desaparición de obstáculos para el acceso a la justicia ambiental: reconocimiento en la jurisprudencia del Tribunal Supremo de la legitimación activa a las organizaciones no gubernamentales que trabajan a favor de la protección del ambiente," Revista Aranzadi de derecho ambiental", $n^{\circ}$. 17, 2010, pp. 191-202.

\section{Lista de casos relevantes en materia de legitimación activa en contenciosos ambientales}

Posteriores a la ley 27/2006

- STS 33/2018 de 16 de enero de 2018, Sala Tercera, de lo Contencioso-administrativo, Sección 3a , Rec. 4464/2015, Ponente Calvo Rojas, LA LEY 370/2018, acción "colectiva" de la Ley 26/2007 se constriñe a las materias allí enunciadas

- STS 1188/2017 de 7 de julio de 2017, rec.1783/2015, Sala Tercera, de lo Contencioso-administrativo, Sección $3^{\text {a }}$, Ponente AROZAMENA LASO.LA LEY 121319/2017, "Fundación Oceana" intereses legitimos colectivos.

- STS de 20 de noviembre de 2015, Sala Tercera, de lo Contencioso-administrativo, Sección 5a, Rec. 1203/2014, Ponente SUAY RINCÓN, LA LEY 190983/2015, legitimación Asociación "Salvemos Pontevedra": la asociación sustenta su recurso al amparo del ejercicio de la acción pública reconocida por la Ley de Costas (artículo 109 ).

- STS de 15 de julio de 2015, (Sala de lo Contencioso-Administrativo, Sección $5^{\mathrm{a}}$ ), Recurso de Casación 3492/2013, Ponente NAVARRO SANCHÍS, RJ $\backslash 2015 \backslash 3486$-la legitimación, basada en el ejercicio de la acción pública, es una e inescindible y afecta por tanto al objeto impugnatorio en su integridad-

- STS de 8 de junio de 2015 (Sala de lo Contencioso-Administrativo, Sección $6^{a}$ ), Recurso de Casación 39/2014, Ponente del Riego Valledor, RJ\2015\3166- Legitimación activa: asociación ecologista: impugnación de indulto concedido a condenado por delito medio ambiental: interés difuso en protección del medio ambiente: legitimación existente-. 
- STS de 28 de noviembre de 2014, Sala Tercera, de lo Contencioso-administrativo, Sección 5 ${ }^{\text {a }}$, Sentencia, Rec. 3756/2012, Ponente SUAY RINCÓN, LA LEY 176906/2014, restrcción del ámbito de legitimación del Ministerio Fiscal de conformidad con las previsiones de la LJCA y la LRM.

- STS de 25 de junio de 2014, Sala Tercera, de lo Contencioso-administrativo, Sección 3a, rec. 365/2012, Ponente PERELLÓ DOMÉNEGH, LA LEY 74650/2014 - Permisos de investigación. Impugnación del Real Decreto 547/2012, por el que se otorgan los permisos de investigación de hidrocarburos: No es suficiente su condición de organización o partido político a efectos de reconocerle legitimación para recurrir el Real Decreto impugnado .

- STS de 9 de octubre de 2012, (Sala de lo Contencioso-Administrativo, Sección $3^{\text {a }}$, Recurso de Casación 110/2009, Ponente CAMPOS SÁNCHEZ-BORDONA, RJ 2012\9648, extensión de los criterios sentados en la Ley 26/2007: la interpretación de la concurrencia de los intereses legítimos colectivos respecto de una asociación de vecinos.

- STS de 7 de diciembre de 2011, Rec. 377/2008 Sala Tercera, de lo Contencioso-administrativo, Sección 5 $5^{\text {a }}$ Ponente RODRÍGUEZ-ZAPATA PÉREZ, LA LEY 241514/2011, legitimación activa en materia ambiental de los Ayuntamientos.

- Sentencia de 19 de octubre de 2011, Sala Tercera, de lo Contencioso-administrativo, Sección 5 ${ }^{\text {a }}$, Rec. 4630/2007, Ponente PECES MORATE, LA LEY 229002/2011, legitimación "Institució altempordanesa per a l'estudi i defensa de la natura" (IADEN) contra la resolución, de 8 de noviembre de 2002, de la Consejería de Medio Ambiente, por la que se otorgó autorización ambiental para la explotación de una granja basada en la acción popular urbanísitica.

- STS de 17 de mayo de 2011, Sala Tercera, de lo Contencioso-administrativo, Sección 3a , Rec. 104/2010, Ponente BANDRÉS SÁNGHEZ-CRUZAT, LA LEY 62895/2011,- el art. 45 CE "promueve que todos tengan el derecho a exigir a los poderes públicos que adopten las medidas necesarias para garantizar la adecuada protección del medio ambiente.”-

- Sentencia de 1 de diciembre de 2009, Tribunal Supremo, Sala Tercera, de lo Contencioso-administrativo, Sección Pleno, Rec. 55/2007, Ponente ESPÍN TEMPLADO, LA LEY 233150/2009 -la Ley 26/2007 disipa dudas legitimación asociaciones ecologistas carácter nacional-

- STS de 15 de septiembre de 2009, Rec. 151/2007, Sala Tercera, de lo Contencioso-administrativo, Sección $3^{\text {a }}$, Ponente BANDRES SANCHEZ-GRUZAT, LA LEY 184140/2009- el art. 45 CE promueve que todos tengan el derecho a exigir a 
los poderes públicos que adopten las medidas necesarias para garantizar la adecuada protección del medio ambiente.”-.

- STS de 31 de marzo de 2009, Sala Tercera, de lo Contencioso-administrativo, Sección 3a , Rec. 5119/2006, Ponente BANDRÉS SANCHEZ-CRUZAT, LA LEY 75486/2009, ${ }^{\circ}$ - legitimación de la Asociación plataforma en defensa da ría de Arousa-

- STS de 29 de noviembre de 2006, Sala Tercera, de lo Contencioso-administrativo, Sección 5a, Rec. 933/2003, Ponente FERNÁNDEZ VALVERDE, LA LEY 209629/2006 -legitimación de la Asociación para la defensa del desarrollo ecológico sostenible ex art. 19.1.b y 18.2 LJCA-

Anteriores a la Ley 27/2006

- STS (Sala de lo Contencioso-Administrativo) de 24 de septiembre de 1975 (Ar. 3754, Ponente De MENDIZABAL y ALLENDE)

- STS (Sala de lo Contencioso-Administrativo) de 8 de mayo de 1979, Ar. 2389 (Sala 4a , Ponente MEDINA BALMASEDA)

- STS (Sala de lo Contencioso-Administrativo) de 5 de abril de 1989, Ar. 3233 (Sala $3^{\mathrm{a}}$, Ponente GONZÁLEZ NAVARRO).

-STS de 22 de abril de 2002, Sala Tercera, de lo Contencioso-administrativo, Sección 4 ${ }^{\text {a }}$, Rec. 3799/1997, Ponente XIOL RÍOS, LA LEY 6202/2002

- STS de 19 de enero 2000 (Sala de lo Contencioso-Administrativo, Sección $3^{\mathrm{a}}$ ), Recurso contencioso-administrativo 243/1998, Ponente GONZÁLEZ GONZÁLEZ RJ $\backslash 2000 \backslash 20$, admitida participación en la elaboración de la norma reglamentaria ambiental no cabe denegar legitimación para impugnar

- STS de 24 de diciembre de 2001, Sala Tercera, de lo Contencioso-administrativo, Sección 5a , Sentencia Rec. 347/1999, Ponente ENRÍQUEZ SANCHO, LA LEY 233252/2001, legitimación activa de Ecologistas en Acción CODA en la sustanciación de un recurso referente a la autorización de un almacén de residuos radiactivos, la "asociación recurrente goza de la legitimación que le reconoce el artículo 19.1 b de la Ley de la Jurisdicción".

- STS de 20 de septiembre de 2004, Rec. 2874/2001, Sala Tercera, de lo Contencioso-administrativo, Sección $3^{\text {a }}$, Ponente TRUJILLO MAMELY, LA LEY 2190/2004, - Legitimación del Ayuntamiento para impugnar el acto, aunque la línea eléctrica no esté situada en su territorio, al estar interconectados los puntos eléctricos y depender unos de otros, teniendo interés indirecto o difuso.-. 